\title{
Verzeichnis der Abbildungen und Tabellen
}

Abb. 1. Grundlegende Vorgänge der Übermittlung sprachlicher Informationen (schematisiert) . . . . . . . . . . . . . . . . . . . . . 6

Abb. 2. Beziehungen der Phonetik zu angrenzenden Wissenschaften . . 25

Abb. 3. Arbeitsschritte der experimentellen Methode . . . . . . . . 40

Abb. 4. Sprachfunktionales System (schematisiert) . . . . . . . . . 47

Abb. 5. Vorgänge bei der Genese lautsprachlicher Zeichen . . . . . . 51

Abb. 6. Organe des Atemtraktes . . . . . . . . . . . . . . . . . 55

Abb. 7. Bronchialbaum innerhalb der (aufgeschnittenen) Lungenflügel $\quad 57$

Abb. 8. Rippenkorb . . . . . . . . . . . . . . . . . . . . . . 59

Abb. 9. Zusammenhang von Atmung und Haltung . . . . . . . . . 62

Abb. 10. Verfahren der Pneumographie (a und b) . . . . . . . . . 65/66

Abb. 11. Luftvolumina bei der Atmungstätigkeit . . . . . . . . . . . 68

Abb. 12. Kehlkopf in Atmungs- und Schluckstellung . . . . . . . . . 71

Abb. 13. Knorpelgerüst des Kehlkopfes . . . . . . . . . . . . . . 73

Abb. 14. Mechanismus der Stimmlippendehnung . . . . . . . . . . $\mathbf{7 4}$

Abb. 15. Grundeinstellungen der Glottis . . . . . . . . . . . . . . 77

Abb. 16. Mundschreiber- und Kehltonkurve der Stimmeinsätze . . . . 79

Abb. 17. Mechanismus der Stimmlippenschwingungen . . . . . . . . 81

Abb. 18. Querschnitt des Kopfes mit Bezeichnung der Hohlräume . . . 88

Abb. 19. Einstellungen der Lippen . . . . . . . . . . . . . . . . . 90

Abb. 20. Veränderungen des Ansatzrohres in der Längendimension (schemstisiert) . . . . . . . . . . . . . . . . . . . . . 95

Abb. 21. Querschnittsdarstellung des Ansatzraumes . . . . . . . . . 97

Abb. 22. Formen für die auditive Verarbeitung lautsprachlicher Zeichen 104

Abb. 23. Schematische Darstellung des Ohres . . . . . . . . . . . . 110

Abb. 24. Querschnitt durch das Innenohr . . . . . . . . . . . . . . 112

Abb. 25. Modell der Schnecke (nach v. Békésy) . . . . . . . . . . . 113

Abb. 26. Schema der Hörbahn . . . . . . . . . . . . . . . . . . 116

Abb. 27. Lage des Hörfeldes im Schallfeld . . . . . . . . . . . . . 122

Abb. 28. Hörfeld mit Linien gleicher subjektiver Lautstärkeempfindung (Isophonen) . . . . . . . . . . . . . . . . . . . . . . 124

Abb. 29. Abhängigkeit der Tonkennzeit von der Frequenz . . . . . . 125

Abb. 30. Hörfeld mit Angabe der akustischen Differenzierungslejstung für Töne . . . . . . . . . . . . . . . . . . . . . . . . 128 
Abb. 31. Hörfeld mit Mithörschwellen . . . . . . . . . . . . . . . 131

Abb. 32. Zeitverlauf der Readaptation (Nachverdeckung) für gaußförmige Rauschimpulse . . . . . . . . . . . . . . . . . 132

Abb. 33. Wirkung der Schallquellenlokalisation . . . . . . . . . . . 134

Abb. 34. Analyse-Synthese-Prozeß beim Hören . . . . . . . . . . . 141

Abb. 35. Kurven des Schalldruckverlaufs . . . . . . . . . . . . . 151

Abb. 36. Unterteilung des Hörschallbereiches . . . . . . . . . . . . 152

Abb. 37. Überlagerung (Superposition) von zwei Sinusschwingungen . . 155

Abb. 38. Linienspektrum des gleichen Klanges (Vokal o) . . . . . . . 157

Abb. 39. Abklingende Schwingungen . . . . . . . . . . . . . . . 159

Abb. 40. Mehrfache Informationsübermittlung mittels Impulskodierung $\mathbf{1 6 0}$

Abb. 41. Prinzipdarstellung des Magnettonverfahrens . . . . . . . . 167

Abb. 42. Meßschleife eines Schleifenoszillographen . . . . . . . . . . 170

Abb. 43. Blockschaltbild eines Kathodenstrahloszillographen . . . . . 171

Abb. 44. Automatisch extrahierter Verlauf der Grundfrequenz . . . . . 174

Abb. 45. Oszillogramm zusammenhängender Sprache . . . . . . . . 176

Abb. 46. Dynamikverlauf zusammenhängender Sprache, mit verschiededener Zeitkonstante integriert . . . . . . . . . . . . . . 177

Abb. 47. Sonagramm des Vokals i mit gleitender Grundfrequenz . . . . 181

Abb. 48. Felder der Realisationsformen für verschiedene Vokslphoneme in einem $F_{1} / F_{2}$-Zuordnungsschema (nach Peterson und Barney) . . . . . . . . . . . . . . . . . . . . . . . .

Abb. 49. Formantkarte mit den (amerikanischen) Vokaldreiecken für die Männer-, Frauen- und Kinderstimme (nach Peterson) . . . 183

Abb. 50. Spektrogramm eines stimmlosen S-Lautes . . . . . . . . . 184

Abb. 51. Spektrogramm eines stimmhaften S-Lautes . . . . . . . . . 185

Abb. 52. Blockschaltbild eines Suchtonanalysators . . . . . . . . . 187

Abb. 53. Vereinfachte Prinzipdarstellung eines Visible-Speech-Gerätes (nach Flanagan) . . . . . . . . . . . . . . . . . . . . 189

Abb. 54. Sonagramm eines zusammenhängenden Textes . . . . . . . 192

Abb. 55. Artikulationsstellen . . . . . . . . . . . . . . . . . . . 213

Abb. 56. Veränderung des 1., 2. und 3. Formanten bei Querschnittsänderung im Ansatzrohr . . . . . . . . . . . . . . . . . 215

Abb. 57. Lage der Formantpunkte . . . . . . . . . . . . . . . . 225

Abb. 58. Zusammenhang der mel-Skala mit der logarithmischen und der linearen Frequenzskala $\quad . \quad$. . . . . . . . . . . . . . . . 225

Abb. 59. Modell des aus zwei Komponenten zusammengesetzten Ansatzrohres (nach Flanagan) $\quad$. . . . . . . . . . . . . . . . . . . . . 226

Abb. 60. Formantänderungen bei einem Zweikomponenten-Modell des Ansetzrohres . . . . . . . . . . . . . . . . . . . . . . 227

Abb. 61. Formantänderungen für ein Zweikomponenten-Modell verschiedener Gesamtlänge . . . . . . . . . . . . . . . . . 228

Abb. 62. Formantdaten für die (amerikanischen) Vokale nach Peterson . 231

Abb. 63. Vokalviereck der deutschen Vokale . . . . . . . . . . . . 235

Abb. 64. Vokalvierecke wichtiger europäischer Sprachen . . . . . . . 242 
Abb. 65. Palatogramm des sch-Lautes in der Lautfolge Busch . . . . . 257

Abb. 66. Überlappung der akustischen Eigensehaften von Lauten im zusammenhängenden lautsprachlichen Zeichen . . . . . . . 278

Abb. 67. Zusammenhang zwischen der Anzahl zweigliedriger Lautfolgen und ihrer relativen Gebrauchshäufigkeit . . . . . . . . . .

Abb. 68. Affinitätsfaktoren für Lautfolgen innerhalb der Silben und an Wort- und Silbengrenzen im zusammenhängenden Text . . . 283

Abb. 69. Häufigkeit von deutschen Einsilbern mit einer bestimmten Lautanzahl im deutschen lexikalischen Wortschatz (nach Menzerath) . . . . . . . . . . . . . . . . . . . . . . 294

Abb. 70. Anlautstrukturen in deutschen Silben . . . . . . . . . . . 295

Abb. 71. Auslautstrukturen in deutschen Silben . . . . . . . . . . . 296

Abb. 72. Häufigkeit von rhythmischen Strukturen mit einer bestimmten Silbenzahl im zusammenhängenden deutschen Text . . . . . 305

Tabelle 1 Zeichen für die phonetische Umschrift nach der API . . . . . 208

Tabelle 2. Statistik über die Architektur des deutschen Wortschatzes (nach Menzerath) . . . . . . . . . . . . . . . . . . . . 237 